American Journal of Pharmaceutical Education 2019; 83 (1) Article 6508.

\title{
RESEARCH
}

\section{An Integrated Dyspepsia Module for First-year Pharmacy Students}

\author{
Cristina I. De Matteis, PhD, ${ }^{a}$ Michael D. Randall, PhD, ${ }^{\mathrm{b}}$ Eleanor J. Harvey, MPharm, ${ }^{\mathrm{a}}$ Andrew Morris, \\ $\mathrm{PhD},{ }^{\mathrm{c}}$ G. Sebastiaan Winkler, PhD, ${ }^{\mathrm{a}}$ Helen F. Boardman, $\mathrm{PhD}^{\mathrm{a}}$ \\ ${ }^{a}$ School of Pharmacy, The University of Nottingham, Nottingham, United Kingdom \\ ${ }^{\mathrm{b}}$ School of Life Sciences, The University of Nottingham, Nottingham, United Kingdom \\ c School of Pharmacy, The University of Nottingham, Malaysia Campus, Kuala Lumpur, Malaysia \\ Submitted May 6, 2017; accepted July 28, 2017; published February 2019.
}

Objective. To design an integrated dyspepsia module for first year pharmacy students that combines clinical and professional practice with fundamental sciences in five different science subject areas. Methods. The approaches used in designing this module are described with emphasis on strategies adopted to integrate science and practice, and the new ways of working adopted by the design team. Students' views and experiences of the module and its integration were explored using questionnaires. Results. A high proportion of students reported positive views and experiences of the module, the integration and its impact (as self-reported) on their learning and practice. The assessment of student performance indicated learning and attainment was at an appropriate level for a first-year module. Both the student grades and research results indicate a positive student learning experience.

Conclusion. The dyspepsia module provides a flexible and effective template for the integration of science and practice in theme-based modules, with students reporting positively about the integration, including their perception of its contribution to improving their learning and understanding. New and more collaborative ways of working are required when designing integrated modules.

Keywords: dyspepsia, integrated curriculum, integration of science and practice, integrative learning, themebased

\section{INTRODUCTION}

The integration of science with practice has always been an important component of the discipline of pharmacy, arising from the inherently multi- and inter-disciplinary nature of pharmacy. For example, The Galenic Pharmacy of 1893 describes pharmacy as "The art of applying the laws of Chemistry and Physics to the preparation of drugs in a form suitable for administration in medicine." ${ }^{1}$ In recent years there has been an increasing interest in the integration of science and practice within pharmacy curricula, as a means of supporting the development of pharmacy students' integrative and interdisciplinary skills, with many pharmacy regulatory bodies around the world now mandating effective integration within pharmacy degree programs. In the UK, the most recent 2011 General Pharmaceutical Council $(\mathrm{GPhC})$ standards for the initial education and training of pharmacists stipulate, for the first time, that an integrated experience of science and practice must be provided in the undergraduate Master of Pharmacy (MPharm) degree. ${ }^{2}$ The

Corresponding Author: Cristina I. De Matteis, School of Pharmacy, The University of Nottingham, Nottingham, NG7 2RD, UK. Tel: ++44(0)115951 5038. E-mail: cristina. dematteis@nottingham.ac.uk
Accreditation Council for Pharmacy Education (ACPE) in the United States, the Canadian Council for Accreditation of Pharmacy Programs and the Pharmaceutical Society of Ireland also require curricular integration in degrees that they accredit. $^{3-5}$

In September 2012, the Nottingham School of Pharmacy launched a new MPharm degree program, in which the integration of practice and science is embedded within the curriculum and the design of individual modules from year 1 of the degree. One of the fundamental tenets of this new degree was to combine contemporary clinical training and skills with a rigorous and broad scientific education. The GPhC reinforces the requirement for scientific training by stating (standard 10.4) that "To be safe and effective, the practice of pharmacy must be underpinned by relevant and up-to-date science. Sound science is the basis of effective pharmacy." 2 A similar requirement is mandated by the ACPE 2016 standards, where the provision of "rigorous instruction in all sciences that define the profession" is stipulated, and the foundational sciences of appropriate breadth and depth are described as "central to a contemporary, high-quality pharmacy education."3

One key approach for delivering integration within the University of Nottingham course is through a series of 


\section{American Journal of Pharmaceutical Education 2019; 83 (1) Article 6508.}

11 new Drug, Medicine and Patient (DMP) modules. Each module focuses on a disease state or physiological system. In total, the 11 modules span two years of the four-year program. This paper describes the design of the first of the new integrated DMP modules, the approaches to integration that have been developed, and the processes and ways of working that the authors used in creating this module. The latter is included because the authors' experiences suggest the need for different ways of operating when creating integrated content of this type. The dyspepsia module was designed as both the first DMP module that students would encounter, and also as a flexible template to use in the development of 10 future DMP modules. During the first year of delivery, research was performed to explore the experiences of the students to the integrated module.

The dyspepsia module provides an integrated description of the science and practice that underlies the treatment of dyspepsia. As such, the module contributes to GPhC standard 5, which is the requirement for an integrated experience of science and practice. ${ }^{2}$ The dyspepsia module also incorporates standard 1 of the ACPE standards and educational outcome 1.1 of the Center for Advancement of Pharmacy Education (CAPE), which both stipulate the requirement for the learner to "develop, integrate, and apply knowledge from the foundational sciences to evaluate the scientific literature, explain drug action, solve therapeutic problems, and advance population health and patient-centered care."

Integration within education has been described as the "intentional uniting or meshing of discrete elements or features" within the learning experience. ${ }^{7}$ The Association of American Colleges and Universities defines it as "an understanding and a disposition that a student builds across the curriculum and co-curriculum, from making simple connections among ideas and experiences to synthesizing and transferring learning to new, complex situations within and beyond the campus." "Integration in learning aims to develop an individual capable of connecting concepts to face new challenges and tackle future problems. It is not limited to the curriculum, but continues throughout one's personal and professional development as a member of an ever-changing society. ${ }^{9}$

The idea of integration within learning is well established in higher education, with the focus more recently appearing to move toward educators designing and delivering integrated curricula, rather than students performing the integration entirely by themselves. ${ }^{10}$ Intentional integrated teaching strives to enhance students' capacities to connect concepts and to design assessment opportunities that test these capacities. The teaching should foster an intentional learning mindset, whereby students find purpose from their learning, reflect on it and become self-aware of the integration taking place. $^{11}$

An opportunity afforded by integration may be in supporting the inter- or multi-disciplinary learning required in pharmacy, where the educational demands placed on pharmacy students (and pharmacists) are appreciable, as they are required to grasp and understand threshold concepts in a range of different discipline areas (eg, chemistry, biology, clinical practice). Threshold concepts within disciplines illustrate "conceptual gateways" which, when crossed, lead to a transformed way of thinking that allows progression to a deeper level of understanding. ${ }^{12}$ However threshold concepts may also become "troublesome" knowledge. For example, inert knowledge is "troublesome" as it remains unused by the learner due to a failure to relate it to real life; conceptually difficult knowledge becomes "troublesome" when it is complex, hard to grasp or seems illogical. ${ }^{12-14}$ This would suggest that integrative approaches to learning may support pharmacy students in the challenges presented by the range of threshold concepts from different disciplines that they are required to master, by presenting clear links, context, sequence and logic in the subject material under study. Indeed it has been reported that when thresholds are crossed and understanding is reached, novel conceptual connections can be made, contributing to the process of integrative learning. ${ }^{12}$

The increased interest in integrated pharmacy curricula is demonstrated by two recent reviews in this area, and two recent surveys exploring the extent of curricular integration in US pharmacy degrees. ${ }^{10,15-17}$ It is clear that what constitutes curricular integration is interpreted in many different ways, and aims to deliver a variety of different teaching and learning outcomes. Harden suggests that there are varying degrees of integration that lie on a continuum from "isolation," where no linking of concepts is attempted, to "trans-disciplinary," where in a real-life practice situation students are able to integrate content themselves. ${ }^{18}$ Pearson and Hubball suggest useful areas of inquiry when evaluating curricular integration, which include "how have instructors approached the task of implementing curricular integration?," and "what are the drivers, barriers, and pedagogical supports that affect curricular integration, from student and faculty perspectives?" 10 Our paper, together with providing a description of the new dyspepsia module, presents our experiences in the two areas of inquiry as suggested by Pearson and Hubball. Poirier and colleagues suggest that an area for future curriculum enhancement is the integration of a wider range of disciplines in addition to the commonly reported pharmacology, pathophysiology, medicinal chemistry and therapeutics. ${ }^{17}$ The generic module template described here provides a potential means for addressing this, where the inclusion of diverse fundamental science, practice 


\section{American Journal of Pharmaceutical Education 2019; 83 (1) Article 6508.}

and clinical content is facilitated and supported. Within the dyspepsia module, seven different subject areas are included.

The integration of science with clinical practice is a familiar approach and aspiration within medical education. Early pioneering work in this area includes the McMaster approach in Canada and the Dundee curriculum in Scotland. ${ }^{19,20}$ Similarly, dentistry degree programs have also explored this approach, and rarer examples can be found of integration of science with practice in nursing and physiotherapy degree curricula. ${ }^{21-25}$ There has been a steady expansion in the popularity and incidence of integrated curricula for medicine in recent years, and with this expansion has come the recognition that the term "integration" has been interpreted in many different ways, and what constitutes integration in different settings varies considerably. ${ }^{26}$ Two recent reviews of the integrated curriculum in medicine have provided detailed commentary on this expansion and the current state of play. ${ }^{26,27}$ Many key areas where future work and improvements would be of value have been identified, and include ensuring the collaborative design and synchronous delivery of integrated courses by a multidisciplinary team consisting of scientists and clinicians; and maintaining a strong fundamental science content, both in terms of the emphasis and depth of science coverage in integrated modules at all stages/levels of medical education, but also including an increasing number of science subject areas, as these become essential to understanding new areas of medicine. ${ }^{26}$ The new dyspepsia module and the approaches to collaborative working described in this paper, while designed with pharmacy in mind, may also provide interesting perspectives for colleagues in medical education.

The dyspepsia module has been designed as the first of a series of 11 integrated modules within the Nottingham pharmacy (MPharm) degree, and hence as a prototype module, to be easily customized to create other diseaseand system-based courses or modules. As such the prototype described here would also be easily generalizable to other pharmacy schools, and more widely in medical and health care higher education, where the integration of clinical and professional practice with robust and diverse fundamental science content, is a curricular requirement.

\section{METHODS}

The dyspepsia module is the first of the DMP modules and runs over a dedicated four-week block at the start of the second semester of the first year. It comprises a wide range of different teaching activities, including patient narrative-based case studies, lectures, laboratory practicals, professional practice dispensing classes, and small group workshops, all of which have been designed to provide an integrated description of dyspepsia, where dyspepsia is used in its widest sense as an umbrella term to cover a range of diseases of the upper gastrointestinal tract. Seven subject areas are taught, also known as the vertical themes, of which two are practice related (pharmacy and clinical practice; professionalism and leadership) and five scientific (pharmacology and therapeutics; biology and physiology; pharmaceutics; pharmaceutical chemistry; and absorption, distribution, metabolism and excretion or ADME). The initial design and development of the module spanned over a two-year period. The module was delivered for the first time in the 2012/13 academic year.

The module design team consisted of five academic staff, each taking responsibility for one or two of the vertical subject themes (Table 1). In each case, the vertical themes were the subject expertise of the staff, who were all research active in these areas. One member of the team was the lead for the module with overall responsibility for the design and delivery of the module. Two members of the team are $\mathrm{GPhC}$-registered pharmacists. One person was responsible for the delivery of each subject area, so that students would associate a given person with a given subject theme. As the first DMP module that students would encounter, clear signposting of the structure and content was felt to be important, hence having a specific "face" associated with each subject area was hoped to contribute to this labelling. This also allowed the team to reduce the number of staff teaching the module, and create a tighter knit, closer and more accessible community of teachers.

Developing theme-based integrated content across seven subject areas was new to the members of the design team despite their being experienced teachers of pharmacy undergraduate courses. They had all used integrated approaches in past modules, but this generally involved integration across two or three subject areas. The team's goal for the dyspepsia module (and the generalizable prototype that would ensue) was to develop wider and higher level integration, which, if one considers Harden's integration ladder, could be interpreted as the module, or elements of it, being within the top third of the ladder. ${ }^{18}$ To achieve this, monthly design meetings were attended by all five members of the design team. On occasions, other staff were invited to join these meetings, when additional expertise and advice was required, or additional content and teaching activities were needed. The design process thus included regular roundthe-table discussions and group-working between all the subject leads. This represented a new way of developing teaching content for all of the team members as they relied on significantly more sharing of ideas and discussion than in past teaching. 
American Journal of Pharmaceutical Education 2019; 83 (1) Article 6508.

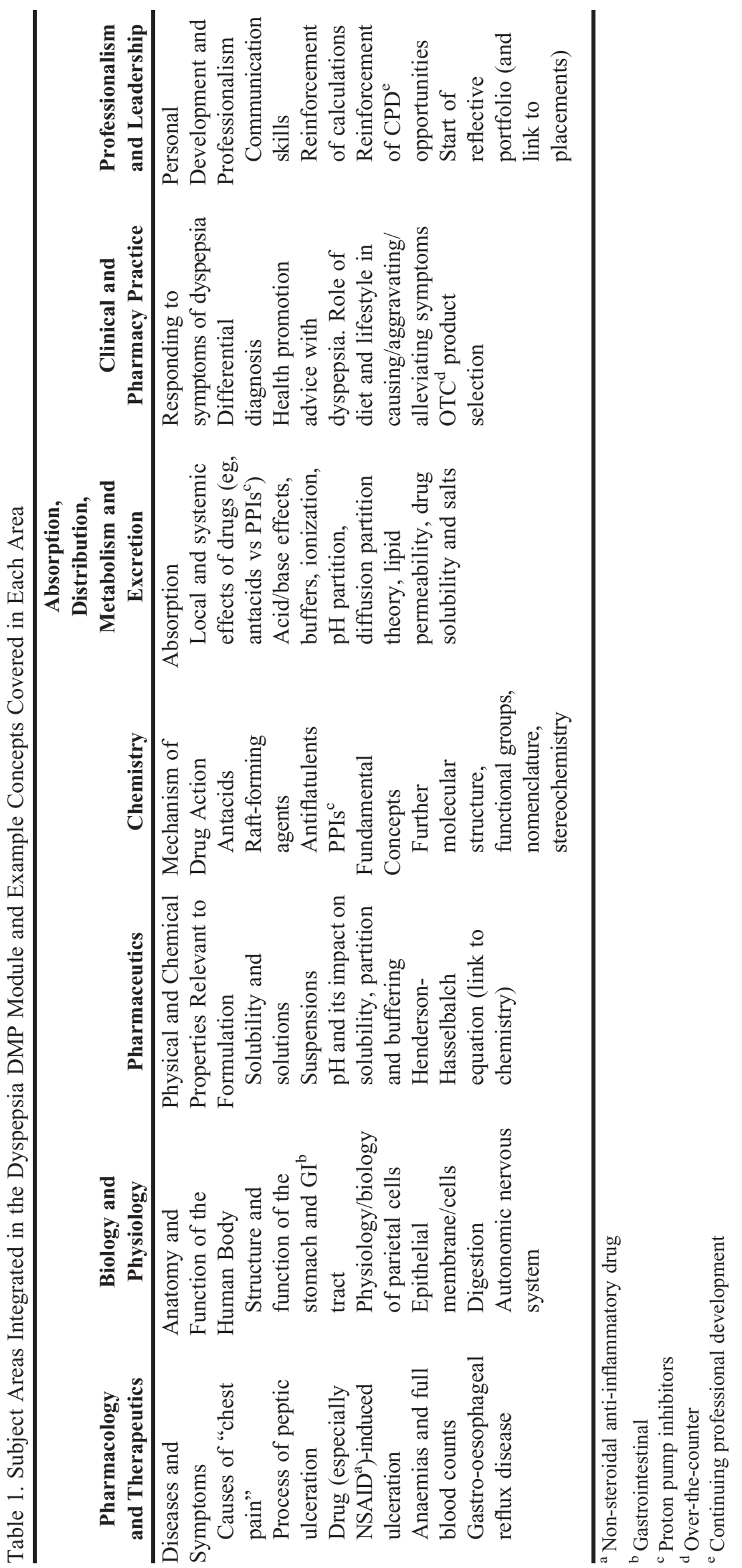




\section{American Journal of Pharmaceutical Education 2019; 83 (1) Article 6508.}

The following steps were adopted in the design of the module:

Module Narrative. To help decide when and how different content should be delivered, in which order, and at what level of difficulty and detail, a narrative for the module was defined (Figure 1). This allowed the team to begin designing the horizontal integration in the module, of which the integration of science with practice, and practice with science, were key components. ${ }^{7,15}$ The narrative allowed content to progress from simple to more challenging and provided the clinical perspective used when writing teaching material across all themes. It is worth stressing that the narrative was the starting point when writing all the teaching material, and as such was embedded within all the subject themes. The narrative was mapped onto a four-week timetable, allowing the team members to define an order for delivery of content in each of the seven subject themes. Within each of the vertical subject themes the content was delivered in an order that ensured a coherent subject narrative (ie, effective vertical integration), together with close timings in the delivery of integrated content by different subject themes. ${ }^{7,15}$ The plan was that integrated content arising from the different vertical themes should be experienced by the students in relatively close succession (ie, synchronously) within the four-week block.

Case Studies. A series of patient narratives were created to bring real-life patient experiences to pharmacy students, while also creating opportunities for students to develop their integrative learning, as they use their scientific knowledge and skills to understand clinical situations and develop their clinical and professional practice. The aim was to simulate authentic clinical scenarios in a variety of pharmacy work spaces, which progressed over time, often in unexpected ways, to create immersive and integrative learning for the students. Clinical case study-based teaching incorporating the patient narratives was developed as an integral part of the student learning experience within the module. ${ }^{28}$ Centered on inquirybased learning, the case studies were designed to support student-centered learning and to highlight the links between the seven themes and the relevance to practice.

Visually-rich, interactive case study material was created, which included customized videos, photographs, images, and interactive 3D molecular graphics, and was delivered via the open source web-based platform Xerte (Apereo, Princeton, NJ). ${ }^{29}$ In a series of staff-facilitated small group workshops (eg, three groups of five students each per workshop), students worked through questions and concepts associated with the case studies using resources found online. Feedback provided during these sessions, from peers and staff, developed students' abilities and skills in independent problem-based learning. The case study teaching (Xerte and internet browsing) was delivered using iPads in the timetabled workshops, with students expected to also review the online material outside of the workshops.Laboratory Practicals. A series

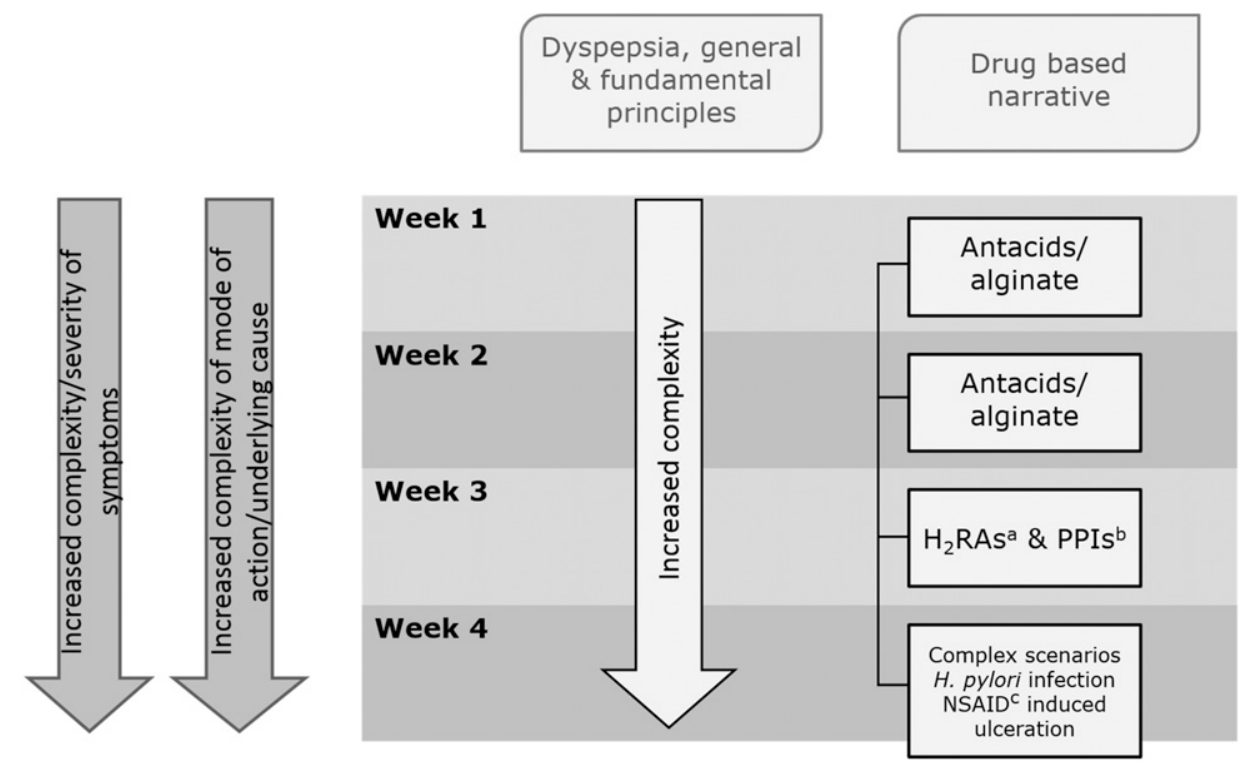

Figure 1. Narrative Structure for the Dyspepsia Module Mapped onto the 4-week Timetable.

${ }^{\text {a }}$ Histamine $\mathrm{H}_{2}$-receptor antagonists

${ }^{\mathrm{b}}$ Proton pump inhibitors

${ }^{\mathrm{c}}$ Non-steroidal anti-inflammatory drug 


\section{American Journal of Pharmaceutical Education 2019; 83 (1) Article 6508.}

of new laboratory experiments were written to develop students' practical skills, ability to record and analyze data, and to integrate science and practice within the module. The four new experiments included manufacturing of medicines relevant to dyspepsia, exploration of the chemical properties of proprietary medicines and pharmaceutical chemistry analysis. In all cases, these experiments and their results were integrated with practice. Students were able to manufacture their own specials medicines, ie, pharmaceutical compounding, in the form of an antacid suspension as described in the British Pharmacopoeia, and a modified antacid powder blend. ${ }^{30}$ These were then analyzed for their acid neutralizing capacity using British Pharmacopoeia methods, and their performance assessed in a variant of the Rossett-Rice test. ${ }^{30-32}$ Students were also able to investigate how the chemical composition of proprietary alginate medicines affected their raft (barrier) forming ability, and to observe how formulation and ingredients affected the anti-foaming ability of proprietary antiflatulent medicines.

Further Signposting of the Horizontal Integration. Lectures and small group problem-solving workshops were used to deliver a sizeable proportion of this module, in addition to the case study teaching and practicals. To help students understand the horizontal integration between the lectures from different subject specialists, extensive use was made of both visual and verbal cues to highlight connections and links, together with joint presentation of lectures. For example, the integration of content was highlighted to students by showing relevant slides from different subject specialists' lectures within one's own lectures. Joint lectures allowed a common topic to be delivered by two different subject specialists, providing an alternative approach to labeling integration. On one occasion, three lectures on omeprazole from three different subject perspectives were delivered in succession, again highlighting connections.

Since this was the first of the DMP modules that year 1 students had come across, the decision was made to clearly highlight and label lectures as being associated with one of the seven vertical themes. This was felt to be important so that students could understand, at this early stage, the name and content of these subject areas, which has considerable importance in understanding the nature of academic disciplines and how academic content is organized and labeled, including the likely location of textbooks in libraries. ${ }^{33}$ The reduction or removal of this level of labeling as students progress through the DMP modules is likely to be desirable, to allow students to further develop their own integrative learning. ${ }^{9,10,15}$

Assessment. The syllabus and learning outcomes for this module and the level at which they would be taught and assessed were defined as part of the early stages of the overall new MPharm course design process at the University of Nottingham. All 11 prospective DMP modules, together with the modules that were to precede and follow, defined a skeleton content for their modules. Within these, the main overarching principles to be included were outlined, together with the GPhC learning outcomes to be assessed and at which level of Miller's triangle., ${ }^{2,34}$ The pyramid (or triangular) structure created by Miller provides a framework for the assessment of "clinical skills/competence/performance" in medicine and has been adopted in a variety of health care education settings. This allowed the vertical integration between modules to be explored, and concepts of spiral learning to be developed at an early stage of the course design. ${ }^{35}$ The $\mathrm{GPhC}$ mandates the use of Miller's triangle to assess competencies, together with a spiral curriculum approach, whereby concepts and knowledge are revisited and reinforced throughout the curriculum, but at increasingly complex levels as the course progresses. ${ }^{2}$

The dyspepsia module was assessed by both coursework and summative examinations. The examinations were divided between a short mid-module assessment, from which immediate feedback on performance was provided to candidates, and an end-of-semester assessment. The assessments were designed to assess all the GPhC learning outcomes associated with the module, with questions drawn from any part of the module curriculum. The coursework assessed students' ability to write laboratory reports describing the four experimental practicals, and to answer key questions that explored their knowledge and understanding, together with their ability to integrate science with practice.

Evaluation. Two approaches to evaluating the first year of implementation of the dyspepsia module were a research study of students' views and experiences of the new module and an analysis of the students' performance in the module. University of Nottingham ethics approval and School of Pharmacy permission were obtained prior to the start of the research study. Head of school permission was provided for the analysis of module performance.

A questionnaire was used to capture the views of first year pharmacy students, which was distributed in the timetabled dyspepsia module review lecture on the second to the last day of the module, with dedicated time provided for their completion. Students were emailed 24 hours prior to the session to inform them of the questionnaire distribution. The resulting quantitative data was analyzed using IBM SPSS 22.0 (Armonk, NY). Frequency counts with percentages were calculated. ${ }^{36}$ Data presented in 5-point scales (eg, strongly agree, agree, neutral, disagree and strongly disagree) were collapsed to 3-point scales (agree, neutral, disagree) for analysis. 


\section{American Journal of Pharmaceutical Education 2019; 83 (1) Article 6508.}

The questionnaire also contained a 5-point "symbolbased" scale incorporating smiley face type emojis, which was re-categorized to a 5-point scale reflecting degree of happiness/unhappiness (ie, very happy, happy, neutral, unhappy, very unhappy).

To determine student performance during the first year of delivery, the new module was compared with a previous module that contained some of the same science, namely the former first year pharmaceutical chemistry module. In the previous MPharm course, the clinical and professional aspects of the dyspepsia module were delivered at various stages of the program, predominantly in years 3 and 4, with many aspects of the science delivered in later years (eg, physical pharmacy of enteric coatings). This meant that no meaningful comparisons could be made of student learning in the new dyspepsia module and of comparable material in the old program. The new dyspepsia module contains a significant pharmaceutical chemistry content. Hence, the first-year module in pharmaceutical chemistry from the previous program was considered the most useful comparator available. Student module marks on the dyspepsia module (1 year available) were compared to marks on the first-year pharmaceutical chemistry module ( 3 years available). In broad terms, the authors wanted to ascertain whether students were able to demonstrate their learning in an assessment(s) to the expected standard for a first-year module, factoring in the prior qualifications and grades that students arrive onto the program with. The authors believe the above comparison achieves this.

The authors tried to obtain informal feedback from students during the earlier parts of the module, so that any immediate issues could be addressed. Students were encouraged to let the authors know at any point during the module, how they were getting on and what was and was not working well.

Staff Time and Resources Required in Developing the Module. The design and development of the dyspepsia module spanned over two years and involved monthly meetings with all five members of the module design team. Initially, meetings were half-day, then became two hours long, and toward the launch of the module, became one hour long. Between meetings, the members worked creatively on key aspects of the new approach, which was shared, discussed and further developed at subsequent meetings. Monthly meetings were held during the first year, and then as required, with members of the University of Nottingham Learning Technology Team, to discuss and take forward the development of the case studies and the module virtual learning environment (VLE). In the case of the laboratory practicals, workshops and professional practice dispensing classes, other members of academic and technical staff also provided con- siderable input. It is difficult to accurately estimate the cost of creating the dyspepsia module, but the above give some indication of the main activities and personnel involved. It is worth noting that the investment made regarding staff time, IT infrastructure, and other resources has allowed the successful development and delivery of the new dyspepsia module and the template that has served as the foundation for the development of 10 further integrated DMP modules.

\section{RESULTS}

The questionnaire response rate was $83 \%(n=124)$ of the total cohort of students. Male respondents accounted for $31 \%$ of the total number of participants $(n=38)$, and respondents between the ages of 18 and 20 years constituted $92 \%$ of the total number of participants $(n=114)$.

Overall, students reported positive perceptions of the module, with $87 \%$ agreeing $(n=108)$ that they had enjoyed the module, and $90 \%$ agreeing $(n=112)$ that the module content links together effectively to provide an integrated description of dyspepsia and its treatment.

Students' views of the different approaches to integration in the module were overwhelmingly positive (Tables 2 and 3). The case study workshops, responding to symptoms workshop, and practicals received the highest ratings with $87 \%, 79 \%$ and $68 \%$ of students responding with a happy or very happy with these activities. Ninety-one percent of students agreed that case studies effectively integrated all aspects of this module and $89 \%$ agreed that the practicals had helped their understanding of the mode of action of drugs and medicines used to treat dyspepsia.

Students reported positive perceptions of the effect the integration had had on their learning and practice with $82 \%$ agreeing that the integrated approach had enhanced their understanding of the role of the pharmacist, $78 \%$ reporting that it had enhanced their clinical decisionmaking, and $89 \%$ responding that it had aided their learning (Table 4).

Students' performance in the module was positive, as reflected in all three components of assessment, and indicated that the module learning outcomes were successfully met. Grades in the UK are reported as percentages, where $40 \%$ is a pass and $70 \%$ a first class piece of work. The average overall grade for this module was numerically comparable, if slightly higher [67.3\% $(\mathrm{SD}=11.6)]$ than for the pharmaceutical chemistry first year module previously run at Nottingham [64.5\% $(\mathrm{SD}=16.9)]$. In addition, the spread of grades was similar (from the perspective of the examination review processes), indicating that student attainment was typical of a first-year cohort of pharmacy students at the University of Nottingham. The 


\section{American Journal of Pharmaceutical Education 2019; 83 (1) Article 6508.}

Table 2. Students' Feelings Regarding Teaching Methods Used in the Module

\begin{tabular}{lcccc}
\hline & & \multicolumn{3}{c}{ Percentage of Students } \\
\cline { 3 - 5 } & $\mathbf{n}$ & Happy & Neutral & Unhappy \\
\hline Lectures & 122 & 65 & 29 & 6 \\
Case study workshops & 124 & 87 & 12 & 1 \\
Laboratory practicals & 122 & 68 & 23 & 9 \\
Dispensing class & & 63 & 28 & 8 \\
Chemistry workshop $_{\text {Responding to symptoms workshop }}^{60}$ & 122 & 65 & 25 & 10 \\
\hline
\end{tabular}

${ }^{a}$ Half the year group had their dispensing class after the questionnaire distribution

assessment was therefore able to discriminate between different levels of student performance (Table 5). This suggests a successful learning experience for students providing them with opportunities to demonstrate their learning, skills and abilities to the expected standards in the module assessment. However, given the different nature of the content, learning outcomes and assessment/ examinations in the new module and in the new program as a whole, it is difficult to draw further conclusions about changes to student knowledge, skills and performance arising from the new module, or between these two cohorts when compared with previous years.

\section{DISCUSSION}

This article describes the development of a new integrated first year module on dyspepsia, which is also designed to serve as a template for future integrated theme-based modules. From the results of our research exploring students' experiences of the new module, it is clear that the module has worked well, receiving positive feedback from the vast majority of students and showing good levels of student attainment.

The dyspepsia module is the first experience of an integrative approach to learning that year 1 pharmacy students have encountered. Based on their feedback and performance, this transition appears to have worked well. This suggests that our approach of maintaining the visibility of subject areas while attempting to integrate them horizontally has been successful. Spelt and colleagues suggest that knowledge of disciplines remains imperative in integrated curricula, where this "appears to be required for enabling students to step beyond the disciplinary theories and methods in order to make connections between disciplines." 33

Of note from the student responses are the high levels of popularity and positive perceptions of the module and the integration. While this in isolation does not necessarily correlate with pedagogic merit and value, the students have positively engaged with this module. This is particularly reassuring considering that approximately $40 \%$ of the total content within this module (considering both contact time and summative assessment activities) was pharmaceutical chemistry and pharmaceutics, with principles of acid-base chemistry, ionization, solubility and partitioning being covered at length. There was no indication that the students experienced any significant difficulty in engaging with this physical science content.

A 2004 study reported on UK undergraduate pharmacy students' attitudes to the science and practice content within MPharm programs. ${ }^{37}$ Jesson and colleagues indicated that students felt that too much emphasis was placed on fundamental science in the early years of their degrees and that more practice experience from the start of their course would make the content more interesting and help to contextualize the science. ${ }^{37}$ Despite the challenging physical and biological sciences within this

Table 3. Students' Views on Case Study Workshops, Laboratory Practicals and Chemistry Workshops

\begin{tabular}{|c|c|c|c|c|}
\hline & \multirow[b]{2}{*}{$\mathbf{n}$} & \multicolumn{3}{|c|}{ Percentage of Students } \\
\hline & & Agree & Neutral & Disagree \\
\hline $\begin{array}{l}\text { The case study workshops linked together all the aspects of this module to provide an } \\
\text { integrated description of dyspepsia and its treatment. }\end{array}$ & 124 & 91 & 7 & 2 \\
\hline $\begin{array}{l}\text { In laboratory practicals, seeing the medicines in action helped me understand the mode } \\
\text { of action of drugs and medicines used to treat dyspepsia. }\end{array}$ & 122 & 89 & 7 & 4 \\
\hline $\begin{array}{l}\text { The practicals have enhanced my understanding of the clinical effectiveness of some } \\
\text { of the drugs and medicines used to treat dyspepsia. }\end{array}$ & 122 & 87 & 9 & 4 \\
\hline $\begin{array}{l}\text { I found the chemistry workshop a useful tool to consolidate my knowledge from the } \\
\text { lectures. }\end{array}$ & 122 & 74 & 15 & 11 \\
\hline
\end{tabular}




\section{American Journal of Pharmaceutical Education 2019; 83 (1) Article 6508.}

Table 4. Students' Opinions on How Integration Affects Their Learning

\begin{tabular}{|c|c|c|c|c|}
\hline & \multirow[b]{2}{*}{$\mathbf{n}$} & \multicolumn{3}{|c|}{ Percentage of Students } \\
\hline & & Agree & Neutral & Disagree \\
\hline The focus in this module on the "Drug, Medicine and Patient" has facilitated my learning. & 123 & 89 & 9 & 2 \\
\hline $\begin{array}{l}\text { The integration of the science and practice teaching has helped my understanding of my } \\
\text { future role as a pharmacist. }\end{array}$ & 124 & 82 & 15 & 3 \\
\hline
\end{tabular}

module, our students reported that they enjoyed and appreciated the module. Kullgren and colleagues reported similar positive views from pharmacy students with respect to the basic science content in their integrated course in pain management and palliative care. ${ }^{38}$

Students reported that the integration in the module had enhanced their learning and improved their clinical skills and understanding of their professional role. The different approaches to integration in the module were all positively received, with the integration within the case studies and practicals proving popular. Pearson and Hubball reported on the likely individual nature of integrative learning, varying "between students and contexts," and likely to be different from what was perceived or intended by "curriculum planners and instructors." ${ }^{10}$ More detailed discussions with pharmacy students about how they experience integrative learning would be of considerable value as the academy continues to design and develop new integrated teaching and learning.

Our experiences in designing and delivering the dyspepsia module, including the results from the student evaluation of the first year of delivery, were shared with colleagues in the school to support the development of future integrated DMP modules and as part of quality assurance procedures. This process of sharing began one year before the launch of the new program, and continued during and after the new DMP modules were rolled out. Given the success of the first year of implementation, only relatively minor alterations were considered necessary, which included some improvements to the experimental practicals and to the instructions provided to students about the integration. The latter arose from informal conversations with students where it became apparent that some clarifications were needed.

Pearson and Hubball describe potential barriers to the implementation of integration in pharmacy curricular reform, including the "effort in planning and implementation" and "the nature of academic disciplines."10 Similar commentary has been published in relation to curricular integration in medicine. ${ }^{27}$ The demands of an integrated program include communication between subject specialists within one or more modules, agreement on the time given to each discipline, and complicated scheduling of teaching activities. These aspects add to the workload in designing and delivering the program. ${ }^{10,39,40}$ Kullgren and colleagues describe how through "effective planning and communication," academic colleagues were able to "overcome [the] challenges" to create a new integrated module on pain and palliative care for pharmacy students. ${ }^{38}$ In addition, differences in the culture of academic disciplines, in part expressed by their differing threshold concepts, but also their specific traditions, practices and identity, present significant challenges to effective curricular integration for both academic staff and students. ${ }^{10,12,33,40}$ The authors have reported here details of how they collaborated as a multidisciplinary team to create this new module: significant time, increased levels of communication and sharing, together with staff

Table 5. Comparison of Student Grades for the Integrated Dyspepsia Module and Superseded First Year Pharmaceutical Chemistry Module

\begin{tabular}{|c|c|c|}
\hline & $\begin{array}{c}\text { Integrated } \\
\text { Dyspepsia Module }\end{array}$ & $\begin{array}{c}\text { Pharmaceutical } \\
\text { Chemistry Module }\end{array}$ \\
\hline & Percentage of Students ${ }^{\mathrm{a}}$ & Percentage of Students \\
\hline Less than $40 \%$ (fail) & 2.0 & 6.3 \\
\hline $40 \%$ to $49 \%$ & 4.0 & 14.4 \\
\hline $50 \%$ to $59 \%$ & 16.7 & 17.2 \\
\hline $60 \%$ to $69 \%$ & 31.3 & 18.7 \\
\hline $70 \%$ and above (first class) & 46.0 & 43.4 \\
\hline
\end{tabular}

${ }^{\mathrm{a}}$ Grades from single cohort of students $(\mathrm{n}=150), 2012-2013$

${ }^{\mathrm{b}}$ Grades from three cohorts of students pooled $(\mathrm{n}=536), 2009-2010,2010-2011,2011-2012$ 


\section{American Journal of Pharmaceutical Education 2019; 83 (1) Article 6508.}

commitment, were all required in creating the integrated narrative and organisation within the module. Despite these challenges, this has been a rewarding and stimulating process, which has resulted in a close-knit and integrated team. The team consisted of both practicing $\mathrm{GPhC}$ registered pharmacists and non-pharmacy trained pharmaceutical scientists (ie, applied and foundational scientists, respectively, to use the preferred terminology of Bauer and Ferguson), and were also involved in the "synchronous" delivery of the new integrated course. Our approach follows the recommendations by Brauer and Ferguson for best practice (and suggested areas for improvement) in integrated medical curricula. ${ }^{26}$

There are limitations to the data and report. This article describes the design and implementation of a single new module, at a single institution, within the UK, where the pharmacy training involves a master's level undergraduate program of study. As such, this may affect the generalizability of the approach and of the findings to different institutions, countries and programs of study. For example, in the US, pharmacist training is via the professional PharmD degree. In Australia and New Zealand, the bachelor's of pharmacy undergraduate degree is the most common route, while in the UK, students study an MPharm undergraduate degree. Customization of the dyspepsia module and its approach is needed to accommodate varying curricular requirements in different institutions and countries.

Another limitation of this study is its reliance on students' perceptions of the new module. While the results show overwhelmingly positive student perception of the new module, together with areas where students self-report educational value, the study did not directly assess how the new module and its integration affected students' learning and educational outcomes. Such insights would be very valuable.

In addition, the use of smiley face type emojis in a "symbol-based" response scale, and the re-categorization of this scale to reflect degree of happiness or unhappiness is another limitation, since it introduces a further level of interpretation or subjectivity to the analysis.

The dyspepsia module was created as a prototype and flexible template, which has now been successfully customized and used in 10 integrated DMP modules within the Nottingham MPharm degree. Given the generic nature of the template, this could easily be customized to create other theme-based integrated modules, either within pharmacy education or more widely within other health care professions. Features of the template and approach that could easily be customized to different institutional, program or degree subject requirements include the duration and timetabling of the module, the range and type of teaching and learning activities included, the approaches to integration used, and the subject disciplines to be included and integrated within the module. For example, at Nottingham, students enrol and experience one integrated module at a time, for a dedicated four-week block in the case of the dyspepsia module. This could be modified so that the module runs over a longer period of time, simultaneously with the delivery of the other modules. At Nottingham, seven vertical subject themes were incorporated within the template, but the number and choice of subjects could easily be modified to reflect different profession-based, institutional or academic priorities and preferences. As such the template would prove useful in supporting the pharmacy curriculum enhancements suggested by Poirier and colleagues, where the integration of a wider range of disciplines is recommended, together with the issue identified by Bauer and Ferguson, where an increased emphasis on foundational sciences is suggested as a necessary improvement in integrated medical curricula. ${ }^{17,26}$ Based on the spiral curriculum approach, the template is easily customizable to create individual or series of vertically integrated, disease- or system-based modules, where the inclusion of robust and diverse fundamental science content is facilitated, supported and ensured. ${ }^{35}$

\section{CONCLUSION}

This article describes the design and implementation of a new integrated module on dyspepsia, which combines clinical and pharmacy practice with strong fundamental physical and biological sciences. The approach described herein is flexible and is intended for use in other disease- or systems-based integrated modules. The approach provides a simple structure for assisting and ensuring the integration of clinical and professional practice with rigorous multidisciplinary science. Feedback from the first cohort of pharmacy students enrolled in this module is extremely positive with students articulating appreciation of the integration of science and practice. Student attainment also suggests a successful student experience.

\section{ACKNOWLEDGMENTS}

The authors would like to thank Colin Melia, Kevin Shakesheff, Julian Tenney and other colleagues from the University of Nottingham Learning Technology Team for their invaluable feedback about the first year of the new MPharm course.

\section{REFERENCES}

1. Cripps RA. Galenic Pharmacy. London, UK: J \& A Churchill: 1893.

2. General Pharmaceutical Council. Future pharmacists: standards for the initial education and training of pharmacists. 2011. https:// www.pharmacyregulation.org/sites/default/files/document/gphc future_pharmacists_may_2011.pdf. Accessed May 4, 2017. 


\section{American Journal of Pharmaceutical Education 2019; 83 (1) Article 6508.}

3. Accreditation Council for Pharmacy Education. Accreditation standards and key elements for the professional program in pharmacy leading to the doctor of pharmacy degree. Standards 2016. https:// www.acpe-accredit.org/pdf/Standards2016FINAL.pdf. Accessed May 4, 2017.

4. The Canadian Council for Accreditation of Pharmacy Programs. Accreditation standards for the first professional degree in pharmacy programs. 2014. http://ccapp-accredit.ca/wp-content/uploads/2016/01/ CCAPP_accred_standards_degree_2014.pdf. Accessed May 4, 2017. 5. The Pharmaceutical Society of Ireland. Outline accreditation process for the level 8 bachelor degree. 2012. http:/www.thepsi.ie/ Libraries/Education/AccreditationProcess_for_UG_Degree_ Programme_FINAL_1.sflb.ashx. Accessed May 4, 2017.

6. Center for the Advancement of Pharmacy Education. CAPE educational outcomes 2013. http://www.aacp.org/resources/education/ cape/Open\%20Access\%20Documents/CAPEoutcomes2013.pdf. Accessed May 4, 2017.

7. Case R. The anatomy of curricular integration. Can J Educ. 1991;16(2):215-224.

8. Association of American Colleges and Universities. Integrative and applied learning VALUE rubric. In: Rhodes TL, ed. Assessing Outcomes and Improving Achievement: Tips and Tools for Using Rubrics. Washington, DC: Association of American Colleges and Universities; 2010. http://www.aacu.org/value/rubrics/integrativelearning. Accessed May 4, 2017.

9. Huber MT, Hutchings P, Gale R. Integrative learning for liberal education. Peer Review. 2005;7(4):4-7.

10. Pearson ML, Hubball HT. Curricular integration in pharmacy education. Am J Pharm Educ. 2012;76(10):Article 204.

11. Huber MT, Hutchings P. Integrative learning: mapping the terrain. The academy in transition. 2004. http://files.eric.ed.gov/ fulltext/ED486247.pdf. Accessed May 4, 2017.

12. Meyer JHF, Land R. Threshold concepts and troublesome knowledge: linkages to ways of thinking and practicing within disciplines. In: Rust C, ed. Improving Student Learning - Theory and Practice Ten Years On. Oxford, England: OCSLD; 2003: 412-424.

13. Perkins D. The many faces of constructivism. Educ Leadersh. 1999;57(3):6-11.

14. Perkins D. Constructivism and troublesome knowledge. In: Meyer JHF, Land R, eds. Overcoming Barriers to Student Understanding: Threshold Concepts and Troublesome Knowledge. New York, NY: Routledge; 2006:33-47.

15. Husband AK, Todd A, Fulton J. Integrating science and practice in pharmacy curricula. Am J Pharm Educ. 2014;78(3):Article 63.

16. Islam MA, Talukder RM, Taheri R, Blanchard N. Integration of basic and clinical science courses in US PharmD programs. Am J Pharm Educ. 2016;80(10):Article 166.

17. Poirier TI, Fan J, Nieto MJ. Survey of pharmacy schools' approaches and attitudes toward curricular integration. Am J Pharm Educ. 2016;80(6):Article 96.

18. Harden RM. The integration ladder: a tool for curriculum planning and evaluation. Med Educ. 2000;34(7):551-557.

19. Spaulding WB. The undergraduate medical curriculum (1969 model): McMaster University. Can Med Assoc J. 1969;100(14):659-664. 20. Harden RM, Davis MH, Crosby JR. The new Dundee medical curriculum: a whole that is greater than the sum of the parts. Med Educ. 1997;31(4):264-271.
21. Haden NK, Hendricson WD, Kassebaum DK, et al. Curriculum change in dental education 2003-09. J Dent Educ. 2010;74(5): 539-337.

22. Nadershahi NA, Bender DJ, Beck L, Alexander S. A case study on development of an integrated, multidisciplinary dental curriculum. $J$ Dent Educ. 2013;77(6):679-687.

23. Elangovan S, Venugopalan SR, Srinivasan S, Karimbux NY, Weistroffer P, Allareddy V. Integration of basic-clinical sciences, PBL, CBL, and IPE in U.S. dental schools' curricula and a proposed integrated curriculum model for the future. J Dent Educ. 2016; 80(3):281-290.

24. Taylor V, Ashelford S, Fell P, Goacher PJ. Biosciences in nurse education: is the curriculum fit for practice. Lecturers' views and recommendations from across the UK. J Clin Nurs. 2015; 24(19-20):2797-2806.

25. Gannon University, graduate-doctor of physical therapy program, integrated curriculum. http://www.gannon.edu/AcademicDepartments/Physical-Therapy-Department/Graduate/IntegratedCurriculum/. Accessed May 4, 2017.

26. Brauer DG, Ferguson KJ. The integrated curriculum in medical education: AMEE Guide No. 96. Med Teach. 2015;37(4):312-322. 27. Bandaranayake RC. The Integrated Medical Curriculum. London, UK: Radcliffe; 2011.

28. Thistlethwaite JE, Davies D, Ekeocha S, et al. The effectiveness of case-based learning in health professional education. A BEME systematic review: BEME Guide No. 23. Med Teach. 2012;34(6): e421-e444.

29. Xerte Online Toolkits. 2013. Nottingham, UK. https://www. nottingham.ac.uk/xerte/toolkits.aspx.

30. British Pharmacopoeia Volume III. The Stationary Office: 752. 2013.

31. British Pharmacopoeia Volume III. The Stationary Office: 119. 2013.

32. Rossett NE, Rice ML. An in vitro evaluation of the efficacy of the more frequently used antacids with particular attention to tablets. Gastroenterology. 1954;26(3):490-495.

33. Spelt EJH, Biemans HJA, Tobi H, Luning PA, Mulder M. Teaching and learning in interdisciplinary higher education: a systematic review. Educ Psychol Rev. 2009;21(4):365-378.

34. Miller GE. The assessment of clinical skills/competence/ performance. Acad Med. 1990;65(9 Suppl):S63-S67.

35. Harden RM. What is a spiral curriculum? Med Teach. 1999; 21(2):141-143.

36. IBM Corp. Released 2013. IBM SPSS Statistics for Windows, Version 22.0. Armonk, NY.

37. Jesson JK, Langley CA, Wilson KA, Hatfield K. Science or practice? UK undergraduate experiences and attitudes to the MPharm degree. Pharm World Sci. 2006;28(5):278-283.

38. Kullgren J, Radhakrishnan R, Unni E, Hanson E. An integrated course in pain management and palliative care bridging the basic sciences and pharmacy practice. Am J Pharm Educ. 2013;77(6): Article 121.

39. Brueckner JK, Gould DJ. Health science faculty members' perceptions of curricular integration: insights and obstacles. $J$ Int Assoc Med Sci Educ. 2006;16(1):31-34.

40. Stull R, Carter RA. Integrating the pharmacy curriculum: more to consider than improving learning. Am J Pharm Educ. 2002;66(4): 407-410. 